\title{
BMJ Open Association of decreased physical activity due to the COVID-19 pandemic with new-onset neck pain in survivors of the Great East Japan Earthquake: a prospective cohort study
}

Takuya Sekiguchi (D) , ${ }^{1}$ Yoshihiro Hagiwara (D) , ${ }^{2}$ Yutaka Yabe, ${ }^{2}$ Yumi Sugawara (D) , ${ }^{3}$ Ichiro Tsuji, ${ }^{3}$ Eiji Itoi ${ }^{4}$

To cite: Sekiguchi T, Hagiwara Y, Yabe Y, et al. Association of decreased physical activity due to the COVID-19 pandemic with new-onset neck pain in survivors of the Great East Japan Earthquake: a prospective cohort study. BMJ Open 2021;11:e051751. doi:10.1136/ bmjopen-2021-051751

- Prepublication history for this paper is available online. To view these files, please visit the journal online (http://dx.doi. org/10.1136/bmjopen-2021051751).

Received 27 March 2021 Accepted 10 August 2021

Check for updates

(C) Author(s) (or their employer(s)) 2021. Re-use permitted under CC BY-NC. No commercial re-use. See rights and permissions. Published by BMJ.

${ }^{1}$ Department of Orthopaedic Surgery, JR Sendai Hospital,

Sendai, Japan

${ }^{2}$ Department of Orthopaedic Surgery, Tohoku University

School of Medicine, Sendai, Japan

${ }^{3}$ Division of Epidemiology, Department of Public Health and Forensic Medicine, Tohoku University Graduate School of Medicine, Sendai, Japan

${ }^{4}$ Department of Orthopaedic Science, Tohoku Rosai Hospital, Sendai, Japan

Correspondence to Dr Yoshihiro Hagiwara; hagi@med.tohoku.ac.jp

\section{ABSTRACT}

Objectives The COVID-19 pandemic has forced many people to stay at home and to maintain social distancing. This study aimed to assess the association of reduced physical activity during the COVID-19 pandemic with new onset of neck pain (katakori) among a rural Japanese population living in areas damaged by the Great East Japan Earthquake (GEJE).

Design, setting and participants This prospective cohort study has been conducted continuously since 2011 after the GEJE. This study used longitudinal data from 1608 adults who responded to the self-reported questionnaire before and during the COVID-19 pandemic. Changes in physical activity due to the COVID-19 pandemic were categorised into four groups: 'no change', 'decreased by 20\%-30\%', 'decreased by half' and 'almost never go out'. Multiple logistic regression analysis was used to estimate the $\mathrm{OR}$ and $95 \% \mathrm{Cl}$ of the association between COVID-19 pandemic-related physical inactivity and new-onset neck pain.

Results In total, 'no change', 'decreased by $20 \%-30 \%$ ', 'decreased by half', and 'almost never go out' were reported by $9.2 \%, 27.7 \%, 31.2 \%$ and $21.9 \%$ of respondents, respectively. Among them, $9.8 \%$ reported new-onset neck pain. A significantly higher rate of newonset neck pain was observed in participants who reported 'decreased by half' (adjusted OR 1.85, 95\% Cl 1.04 to 3.30 ) and who 'almost never go out' (adjusted OR 2.13, $95 \% \mathrm{Cl} 1.16$ to 3.91 ), compared with those who reported 'no change.'

Conclusions Decreased physical activity has increased due to the COVID-19 pandemic and was significantly associated with new-onset neck pain among GEJE survivors.

\section{INTRODUCTION}

Regular physical activity has beneficial effects on human health such as reducing the risks for obesity, type 2 diabetes, coronary heart disease, some cancers and all-cause mortality. ${ }^{12}$ It is also important for musculoskeletal health, including supporting bone
Strengths and limitations of this study

- This is the first study to examine the association of decreased physical activity due to the COVID-19 pandemic with new-onset neck pain among survivors of a major natural disaster.

- This study used a longitudinal design, requiring protracted efforts from the researchers and survivors to undertake surveys in the aftermath of a disaster.

- The question about physical activity associated with the COVID-19 pandemic was newly generated and has not previously been studied.

- We assessed neck pain using a self-reported and simple question, and therefore, the underlying pathology of pain-related disabilities and the degree of neck pain were not assessed.

- Study participants of this study were residents of disaster areas; however, we could not directly interpret any changes in neck pain caused by the disaster.

and skeletal muscle mass and reducing pain. ${ }^{3-5}$ Physical inactivity has increased due to societal changes and increasingly sedentary lifestyles. Indeed, one out of five adults worldwide was estimated to be physically inactive, which has caused physical inactivity to be recognised as a global pandemic that requires international action. ${ }^{6}$ Indeed, despite WHO's recommendations for regular physical activity, $27.5 \%$ of adults do not meet these guidelines. ${ }^{7}$ Similarly, among the Japanese population, the prevalence of insufficient physical activity among adults was $35.5 \%$ in $2016 .^{8}$

COVID-19 is an infectious disease caused by the SARS-CoV-2, which was first detected in December 2019 in Wuhan, China. ${ }^{9}$ The world is experiencing an extraordinary, life-altering challenge due to the COVID-19 pandemic. 
An increasing number of governments are instituting nationwide quarantines, or considering various forms of lockdown in order to hinder the spread of the novel COVID-19. ${ }^{10}$ In the absence of a preventive vaccine and efficacious pharmaceutical options, public health measures are essential towards containing the spread of the virus. Strict hygienic rules, isolation, quarantine and social distancing have been identified as successful strategies. ${ }^{11}$ Indeed, a rapid review indicated that quarantine measures, such as school closures, travel restrictions and social distancing would reduce the number of COVID-19 infections and deaths. ${ }^{12}$ However, while home isolation and lockdown are likely to decrease physical activity and increase sedentary behaviour, ${ }^{13}$ the impact that the COVID-19 pandemic will have on physical activity levels and physical health remain unclear.

Neck pain is one of the most common symptoms present within the general population. ${ }^{14}$ Similarly, katakori, which presents similarly to neck pain, ${ }^{15} 16$ is also one of the most common subjective symptoms in the Japanese population, with a prevalence of approximately $10 \%{ }^{15}$ Both neck pain and katakori negatively impact the quality of life (QOL) and have become one of the most significant contributors to global disease burden. ${ }^{16} 17$ The disease burden in Japan was further augmented by the Great East Japan Earthquake (GEJE) and the devastating tsunami which hit the northeastern coast of Japan on 11 March 2011. In addition to causing a total of 18440 deaths or missing cases, ${ }^{18}$ the earthquake is associated with chronic and long-term health problems including psychological disorders, physical inactivity and functional disabilities. ${ }^{19}{ }^{20}$ A high prevalence of neck pain was also reported after the GEJE, ${ }^{21}$ which negatively impacted the QOL for survivors. ${ }^{16}$

Insufficient physical activity and back and neck pain are health problems that may persist throughout life. ${ }^{22} 23$ Moreover, neck pain has been reported to be associated with a number of factors, including a lack of physical activity. ${ }^{24}$ Indeed, regular physical activity was reported to protect against neck pain. ${ }^{25}$ We hypothesised that physical activity levels would also decrease due to the COVID-19 pandemic in Japan, and this would increase the prevalence of neck pain. As a result, this study aimed to evaluate the association between COVID-19 pandemicrelated reductions in physical activity with new-onset neck pain among the GEJE survivors.

\section{METHODS}

\section{Study design and participants}

A panel study was conducted on people living in disasterstricken areas such as the Ogatsu, Oshika and Ajishima areas in Ishinomaki city in the Miyagi prefecture in Japan. Initial medical health checks and questionnaire surveys after the GEJE were conducted from June to November 2011. Questionnaire surveys have been repeated every half-year thereafter and remain ongoing. The initial study population was residents registered in the basic residential registry of the Ogatsu, Oshika and Ajishima areas. Although most participants were forced to live in temporary housing after the GEJE, they have now mostly finished moving into permanent housing, including public reconstruction housing and new houses ${ }^{26}$ Given the global spread of COVID-19, we added the questionnaire items about COVID-19 in the 2020 survey (conducted from July to August 2020 during the COVID-19 pandemic). In this work, we linked and analysed the self-reported questionnaire data from May to October 2019 (before the COVID-19 pandemic) to that during the COVID-19 pandemic.

\section{Exposure}

Changes in physical activity due to the COVID-19 pandemic were ascertained by asking the participants 'Has the frequency of going out changed due to the COVID-19 pandemic?'. This item was based on the participants' perception. They were asked to select a selfreported response from the following alternatives: 'no change,' 'decreased by 20\%-30\%,' 'decreased by half,' and 'almost never go out'.

\section{Outcome}

On the basis of the Comprehensive Survey of Living Conditions, we asked the participants whether they had experienced neck pain (katakori) during the past few days. ${ }^{27}$ The question was 'Have you had symptoms within the last few days? If yes, please circle your symptoms' (multiple choices were allowed at the time of the questionnaire). Examples of the possible responses were 'dizziness,' 'irritation,' 'diarrhoea,' 'palpitation,' 'headache,' 'low back pain,' 'shoulder pain,' 'knee pain,' and 'neck pain (katakori)'. ${ }^{28}$ The outcome of interest was new-onset neck pain, which was defined as the presence of neck pain on the questionnaire taken during the COVID-19 pandemic but absent before the pandemic.

\section{Covariates}

On the basis of the previous studies, ${ }^{21}{ }^{29-33}$ the following variables at baseline were included in this analysis as potential confounding factors: sex, age, body mass index (BMI: calculated from self-reported height and weight values), smoking habits, drinking habits, health complications (hypertension, diabetes mellitus and cerebral stroke), employment status, walking time, subjective economic status, living environment, social isolation, psychological distress and sleep disturbance. Subjective economic status was assessed by the question: 'How do you feel about the current state of your household economy?' Available responses were 'fair,' 'poor,' 'poorer' and 'poorest'. Social isolation was assessed by the Lubben Social Network Scale (LSNS-6) and defined by a score of $<12 / 30$ as being socially isolated. ${ }^{34}$ Psychological distress was defined by a score of $\geq 10 / 24$ on the Kessler Psychological Distress Scale-6 (K6). ${ }^{35}$ Sleep disturbance was defined as a score of $\geq 6 / 24$ points on the Athens Insomnia Scale (AIS). ${ }^{36}$ 


\section{Statistical analysis}

Categorical variables were summarised as percentages. Continuous variables were summarised as means with SD. For baseline characteristics, the effect of decreased physical activity during the COVID-19 pandemic (encoded as a categorical variable), was assessed via a $\chi^{2}$ test for categorical variables and one-way analysis of variance for continuous variables.

Crude and multiple logistic regression analyses were performed to analyse the association between decreased physical activity due to the COVID-19 pandemic with new-onset neck pain. We used 'no change' for physical activity as a reference category. The OR and $95 \%$ CI for new-onset neck pain were calculated after simultaneous adjustment for potential covariates. Variables considered in the models were sex, age $(<65$ or $\geq 65$ years), BMI $\left(<18.5,18.5-25, \geq 25 \mathrm{~kg} / \mathrm{m}^{2}\right.$ or unknown), smoking habits (non-smoker, smoker or unknown), drinking habits (non-drinker, $<45.6 \mathrm{~g}, \geq 45.6 \mathrm{~g}$ of alcohol/day or unknown), health complications (hypertension, diabetes mellitus and cerebral stroke), employment status (unemployed, employed or unknown), walking time $(<30 \mathrm{~min} /$ day, $30 \mathrm{~min}$ to $<1$ hour/day and $\geq 1$ hour/day), subjective economic hardship (fair, poor to poorest or unknown), living environment (living in the same house as before the earthquake, new house, public reconstruction housing, other or unknown), social isolation (LSNS-6 score: $\geq 12$, $<12$ or unknown), psychological distress (K6 score: $<10$, $\geq 10$ or unknown) and sleep disturbance (AIS score: $<6, \geq 6$ or unknown) at baseline. Further, we divided the participants into subgroups by age ( $<65$ and $\geq 65$ years) and sex (male and female) and calculated the ORs and 95\% CIs in the same manner. For the stratified analysis, potential multiplicative interactions between neck pain in the first period and age or sex were tested using the Wald test.

All statistical analyses were performed with SPSS V.24.0 (SPSS Japan). All tests were two tailed, and differences at $\mathrm{p}<0.05$ were considered statistically significant.

\section{Patient and public involvement}

The patients and public were not involved in the development of the research questions, outcome measures or study design. The patients were also not involved in the recruitment and performance of the study. We will disseminate the final results to the participants after the results are published in a peer-reviewed journal.

\section{RESULTS}

Among the 3694 participants, 2389 responded to the health survey before the COVID-19 pandemic (response rate: $64.7 \%$ ). Among those, all participants consented to this study and 388 who indicated having neck pain on the questionnaire before the pandemic were excluded from this study. Of the remaining 2001 participants, 1685 responded to the health survey during the COVID-19 pandemic. After excluding 77 participants because of

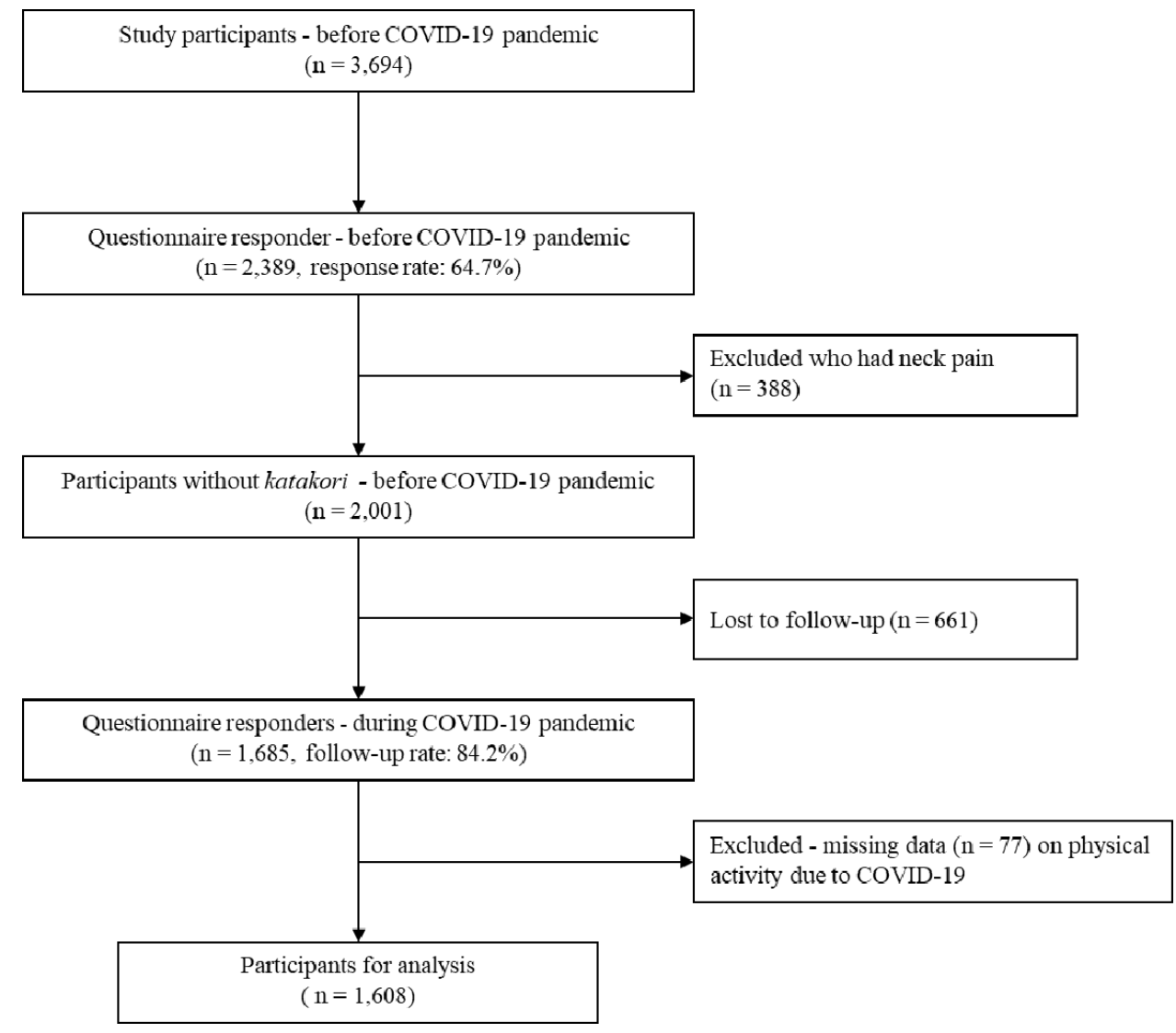

Figure 1 Flow diagram of the participants. 
Table 1 Baseline characteristics according to changes in physical activity due to the COVID-19 pandemic ( $n=1608)$

\begin{tabular}{|c|c|c|c|c|c|}
\hline & \multicolumn{4}{|c|}{ Changes in physical activity due to the COVID-19 pandemic } & \multirow[b]{3}{*}{$P$ value } \\
\hline & No change & Decreased by $20 \%-30 \%$ & Decreased by half & Almost never go out & \\
\hline & $\mathrm{n}=\mathbf{3 0 8}$ & $n=446$ & $\mathrm{n}=\mathbf{2 9 1}$ & $\mathrm{n}=352$ & \\
\hline \multicolumn{6}{|l|}{ Sex (\%) } \\
\hline Female & 53.2 & 49.1 & 46.2 & 38.9 & 0.002 \\
\hline Male & 46.8 & 50.9 & 53.8 & 61.1 & \\
\hline Age (years) & $65.6(19.6)$ & $61.3(18.6)$ & $63.1(18.6)$ & $68.2(20.3)$ & 0.003 \\
\hline \multicolumn{6}{|l|}{ Age (\%) } \\
\hline$<65$ years & 35.7 & 45.3 & 42.0 & 29.5 & $<0.001$ \\
\hline$\geq 65$ years & 64.3 & 54.7 & 58.0 & 70.5 & \\
\hline $\mathrm{BMI}\left(\mathrm{kg} / \mathrm{m}^{2}\right)$ & $23.8(3.5)$ & $24.3(3.6)$ & $24.3(3.6)$ & $23.8(3.6)$ & 0.09 \\
\hline \multicolumn{6}{|l|}{$\mathrm{BMI}(\%)^{*}$} \\
\hline$<18.5$ & 3.2 & 2.2 & 2.0 & 3.2 & 0.001 \\
\hline $18.5-24.9$ & 60.4 & 57.4 & 55.2 & 58.2 & \\
\hline$\geq 25$ & 33.4 & 38.3 & 40.4 & 31.3 & \\
\hline \multicolumn{6}{|l|}{ Smoking habits $(\%)^{*}$} \\
\hline Non-smoker & 75.6 & 79.6 & 81.1 & 80.4 & 0.34 \\
\hline Smoker & 20.5 & 17.0 & 15.3 & 14.5 & \\
\hline \multicolumn{6}{|l|}{ Drinking habits $(\%)^{*}$} \\
\hline Non-drinker & 62.0 & 61.9 & 59.2 & 67.3 & 0.051 \\
\hline$<45.6 \mathrm{~g}$ of alcohol/day & 19.2 & 20.0 & 21.5 & 13.9 & \\
\hline$\geq 45.6 \mathrm{~g}$ of alcohol/day & 10.7 & 8.7 & 9.8 & 6.3 & \\
\hline \multicolumn{6}{|l|}{ Complications (\%) } \\
\hline Hypertension & 41.9 & 39.2 & 42.0 & 48.9 & 0.05 \\
\hline Diabetes mellitus & 9.1 & 9.4 & 8.8 & 9.9 & 0.95 \\
\hline Stroke & 1.9 & 1.3 & 1.2 & 3.7 & 0.045 \\
\hline \multicolumn{6}{|l|}{ Employment status (\%)* } \\
\hline Unemployed & 54.2 & 44.2 & 49.8 & 59.7 & $<0.001$ \\
\hline Employed & 43.2 & 53.8 & 48.0 & 36.6 & \\
\hline \multicolumn{6}{|l|}{ Walking time/day $(\%)^{*}$} \\
\hline$<30 \mathrm{~min}$ & 34.7 & 28.3 & 34.7 & 42.6 & 0.006 \\
\hline 30 min to 1 hour & 32.8 & 40.4 & 36.1 & 31.3 & \\
\hline$\geq 1$ hour & 31.2 & 30.5 & 28.3 & 24.1 & \\
\hline \multicolumn{6}{|l|}{ Subjective economic status (\%) } \\
\hline Fair & 54.2 & 54.9 & 51.2 & 49.7 & 0.68 \\
\hline Poor to poorest & 44.2 & 43.5 & 46.2 & 48.0 & \\
\hline \multicolumn{6}{|l|}{ Living environment (\%)* } \\
\hline Same house as before the GEJE & 30.8 & 31.6 & 30.7 & 35.8 & 0.004 \\
\hline New house & 28.2 & 35.4 & 34.3 & 25.6 & \\
\hline Public reconstruction housing & 27.9 & 21.7 & 24.3 & 20.7 & \\
\hline Other & 13.0 & 11.2 & 10.8 & 17.9 & \\
\hline \multicolumn{6}{|l|}{ Social isolation $(\%)^{\star}$} \\
\hline LSNS-6 score: $\geq 12$ & 64.9 & 78.0 & 75.7 & 71.0 & $<0.001$ \\
\hline LSNS-6 score: $<12$ & 35.1 & 22.0 & 24.3 & 29.0 & \\
\hline \multicolumn{6}{|l|}{ Psychological distress $(\%)^{*}$} \\
\hline K6 score: $<10$ & 91.2 & 92.2 & 90.2 & 83.5 & 0.001 \\
\hline K6 score: $\geq 10$ & 7.1 & 6.5 & 7.6 & 14.8 & \\
\hline
\end{tabular}




\begin{tabular}{|c|c|c|c|c|c|}
\hline & \multicolumn{4}{|c|}{ Changes in physical activity due to the COVID-19 pandemic } & \multirow[b]{3}{*}{$P$ value } \\
\hline & No change & Decreased by $20 \%-30 \%$ & Decreased by half & Almost never go out & \\
\hline & $\mathrm{n}=308$ & $\mathrm{n}=446$ & $\mathrm{n}=291$ & $\mathrm{n}=352$ & \\
\hline AIS score: $<6$ & 76.0 & 72.0 & 71.5 & 69.6 & 0.47 \\
\hline AIS score: $\geq 6$ & 23.4 & 26.9 & 28.1 & 29.8 & \\
\hline
\end{tabular}

Date are shown as percentages or mean (SD).

*Sum of \% does not equal $100 \%$ due to missing data.

AIS, Athens Insomnia Scale; BMI, body mass index; GEJE, Great East Japan Earthquake; K6, Kessler Psychological Distress Scale-6; LSNS-6, Lubben Social Network Scale.

missing physical activity data, 1608 participants were included in the analysis (figure 1).

The mean age of the participants was 63.7 years $(\mathrm{SD}$ : $16.3)$ and $52.2 \%(\mathrm{n}=709)$ were women. Among the participants, 'no change,' 'decreased by $20 \%-30 \%$,' 'decreased by half,' and 'almost never go out' were 9.2\% ( $\mathrm{n}=308)$, $27.7 \% \quad(\mathrm{n}=446), 31.2 \% \quad(\mathrm{n}=502)$ and $21.9 \% \quad(\mathrm{n}=352)$, respectively. The participants who reported new-onset neck pain were $9.8 \% \quad(n=157)$. Baseline characteristics disaggregated by COVID-19 pandemic-related physical activity changes are shown in table 1 .

Table 2 shows the association between decreased physical activity due to the COVID-19 pandemic with new-onset neck pain, as assessed by multivariate logistic regression analysis. A significantly higher rate of new-onset neck pain was observed in participants who reported their physical activity to have'decreased by half' (adjusted OR 1.85, 95\% CI 1.04 to $3.30, p=0.035$ ) and'almost never go out' (adjusted OR 2.13, 95\% CI 1.16 to $3.91, \mathrm{p}=0.014$ ), when compared with the'no change'category. The results of the stratified analysis are shown in table 3. Decreased physical activity showed an interaction with male participants, and those $<65$ years of age, indicating that these populations were particularly at risk for sedentary-associated neck pain. Moreover, there were statistically significant multiplicative interactions between decreased physical activity and these variables.

\section{DISCUSSION}

To our knowledge, this is the first study to investigate the longitudinal association between COVID-19 pandemic-related physical inactivity and neck pain among Japanese populations living in damaged coastal areas. We found that $80.8 \%$ of the participants experienced decreased physical activity due to the COVID-19 pandemic. Furthermore, decreased physical activity during the COVID-19 pandemic was significantly associated with new-onset neck pain.

Physical inactivity, a major risk factor for global mortality, accounts for 3.2 million deaths worldwide each year. ${ }^{37}$ Decreased physical activity can increase the risk of heart disease directly, and also indirectly through increasing the risk for developing other

Table 2 OR and $95 \% \mathrm{Cl}$ of new-onset of neck pain disaggregated by the reduction in physical activity

Changes in physical activity due to the COVID-19 pandemic

No change Decreased by $20 \%-30 \% \quad$ Decreased by half Almost never go out

\begin{tabular}{|c|c|c|c|c|}
\hline No of participants & 308 & 446 & 502 & 352 \\
\hline $\begin{array}{l}\text { No of participants with new } \\
\text { onset of neck pain }\end{array}$ & $18(5.8)$ & 46 (10.3) & $54(10.8)$ & $39(11.1)$ \\
\hline$P$ value & & 0.033 & 0.019 & 0.019 \\
\hline Multivariate OR $(95 \% \mathrm{Cl})^{*}$ & 1.00 (Ref.) & 1.73 (0.96 to 3.12$)$ & 1.85 (1.04 to 3.30$)$ & 2.13 (1.16 to 3.91$)$ \\
\hline
\end{tabular}

*Adjusted for sex (male, female), age ( $<65, \geq 65$ years), body mass index $\left(<18.5,18.5-24.9, \geq 25 \mathrm{~kg} / \mathrm{m}^{2}\right.$, unknown), smoking habits (nonsmoker, smoker, unknown), alcohol drinking habits (non-drinker, $<45.6 \mathrm{~g}$ of alcohol/day, $\geq 45.6 \mathrm{~g}$ of alcohol/day, unknown), complications (hypertension, diabetes mellitus, stroke), employment status (unemployed, employed), walking time ( $\geq 1$ hour, $30 \mathrm{~min}$ to $<1$ hour, $<30 \mathrm{~min}$, unknown), subjective economic status (fair, poor to poorest, unknown), living environment (same house as before the Great East Japan Earthquake, new house, public reconstruction housing, other, unknown), social isolation (Lubben Social Network Scale-6 score: $\geq 12,<12$, unknown), psychological distress (Kessler Psychological Distress Scale-6 score: $<10, \geq 10$, unknown), sleep disturbance (Athens Insomnia Scale score: $<6, \geq 6$, unknown). 
Table 3 Stratified analyses: OR and $95 \%$ Cls of new-onset of neck pain disaggregated by the reduction in physical activity

\section{Changes in physical activity due to the COVID-19 pandemic}

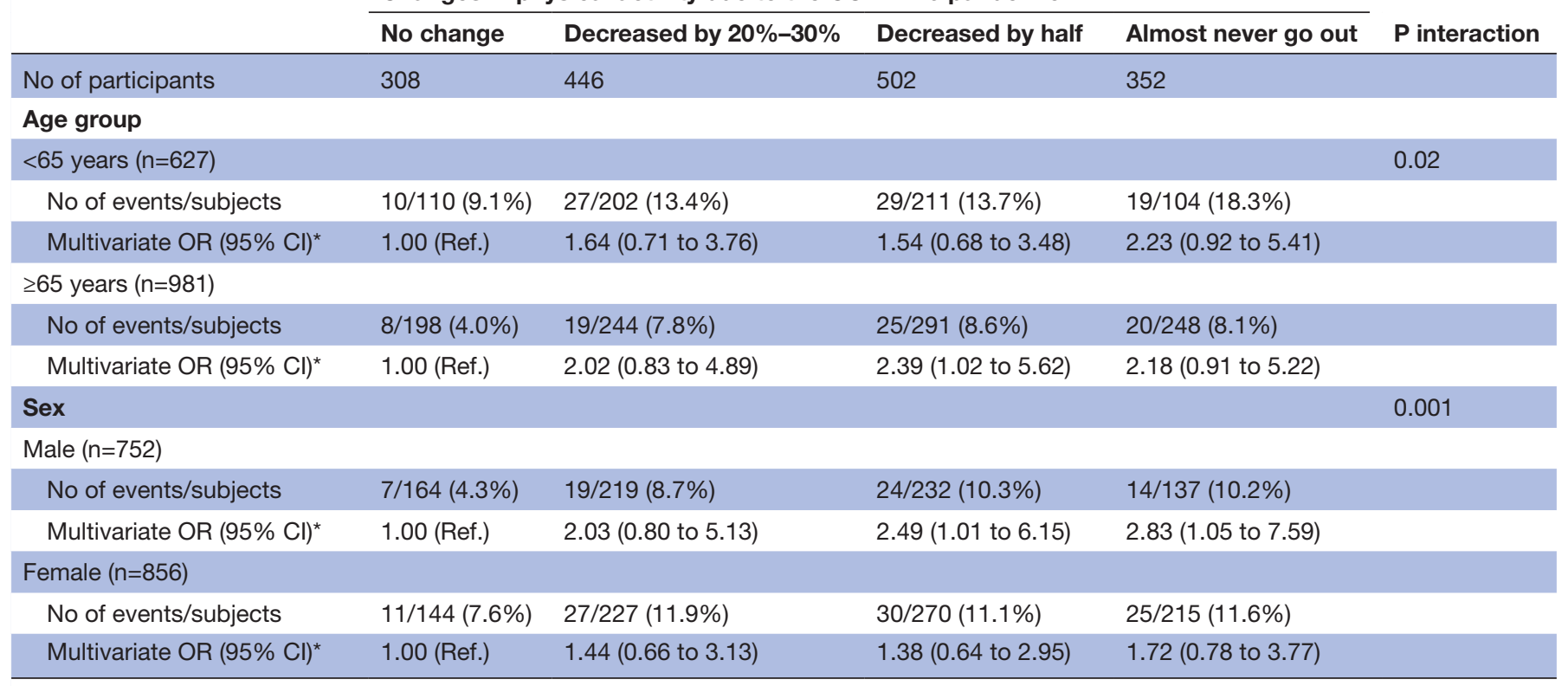

*Adjusted for sex (male, female), age ( $<65, \geq 65$ years), body mass index ( $<18.5,18.5-24.9, \geq 25 \mathrm{~kg} / \mathrm{m}^{2}$, unknown), smoking habits (non-smoker, smoker, unknown), alcohol drinking habits (non-drinker, $<45.6 \mathrm{~g}$ of alcohol/day, $\geq 45.6 \mathrm{~g}$ of alcohol/day, unknown), complications (hypertension, diabetes mellitus, stroke), employment status (unemployed, employed), walking time ( $\geq 1$ hour, 30 min to $<1$ hour, $<30$ min, unknown), subjective economic status (fair, poor to poorest, unknown), living environment (same house as before the Great East Japan Earthquake, new house, public reconstruction housing, other, unknown), social isolation (Lubben Social Network Scale-6 score: $\geq 12,<12$, unknown), psychological distress (Kessler Psychological Distress Scale-6 score: $<10, \geq 10$, unknown), sleep disturbance (Athens Insomnia Scale score: $<6, \geq 6$, unknown).

conditions, such as obesity, high blood pressure, high blood cholesterol levels and type 2 diabetes mellitus. ${ }^{38}$ The fear of being infected and the mobility restrictions imposed during the COVID-19 pandemic may dissuade people from attaining the recommended levels of physical activity. Given the lack of studies employing a similar instrument, it is difficult to compare these findings with other research; nevertheless, this study suggests that the COVID-19 pandemic negatively impacted physical activity among the GEJE survivors.

Musculoskeletal pain, including neck pain negatively impacts the QOL, is a leading cause of disability, and as such is one of the most common reasons for seeking medical advice. ${ }^{17}$ Therefore, only a small reduction in the incidence of neck pain would have a significant beneficial effect for promoting health. In this study, the participants who experienced decreased physical activity had significantly greater chances of new-onset neck pain. This finding is consistent with previous studies, ${ }^{24} 2539$ and thus decreased physical activity may represent a significant predictor of neck pain among the GEJE survivors. Although significant multiplicative interactions were observed, stratified analysis according to the categories of age and sex also showed positive associations between COVID-19 pandemic-related reductions in physical activity and new-onset neck pain. These results, therefore, suggest a robust association between decreased physical activity and neck pain. If sufficiently validated as a true causal association, our study has profound implications for supporting public health. The results of this study would be useful to Japanese populations living in damaged coastal areas and their support structures (eg, family and public health nurses), as well as to clinicians and medical staff who treat musculoskeletal pain. Careful attention and continuous support are needed to improve the physical activity of people during the COVID-19 pandemic, which may affect the onset of neck pain.

This study had several limitations. First, the question about decreased physical activity was newly generated and thus has not been validated previously. ${ }^{40}$ Second, neck pain was only assessed over two periods and changes in the incidence of neck pain across other periods were not evaluated. Further studies with longer follow-up periods are needed. Third, we assessed neck pain using a self-reported and simple question without any additional illustration. Moreover, pain severity and location were not assessed. Finally, the participants of our study were residents of disaster areas, however, we could not directly interpret any changes in neck pain caused by the GEJE.

\section{CONCLUSION}

This study showed that decreased physical activity due to the COVID-19 pandemic was significantly associated with new-onset neck pain. Our study indicates that being active while maintaining social distancing 
is necessary for preventing neck pain among the GEJE survivors.

Acknowledgements We would like to thank the participants of this study. Contributors All the authors have made a substantial contribution to the manuscript and have approved this submission. TS participated in the design of the study and statistical analysis of the data and wrote the manuscript. YH is the corresponding author of this study, participated in the design of the study and helped to draft and edit the manuscript. YS helped to analyse the data and draft the manuscript. YY and El helped to draft the manuscript. IT conceived the study, collected the data, helped to analyse the data and to draft and edit the manuscript.

Funding This work was supported by Health Sciences Research Grants from the Ministry of Health, Labour and Welfare of Japan (H24, 25-Kenki-Shintei-002 [Fukkou])

Competing interests None declared.

Patient consent for publication Not required.

Ethics approval The study protocol was reviewed and approved by the Ethics Committee of Tohoku University Graduate School of Medicine, Sendai, Miyagi, Japan (approval number: 201192). All participants provided informed consent for the study.

Provenance and peer review Not commissioned; externally peer reviewed.

Data availability statement № data are available. Not applicable.

Open access This is an open access article distributed in accordance with the Creative Commons Attribution Non Commercial (CC BY-NC 4.0) license, which permits others to distribute, remix, adapt, build upon this work non-commercially, and license their derivative works on different terms, provided the original work is properly cited, appropriate credit is given, any changes made indicated, and the use is non-commercial. See: http://creativecommons.org/licenses/by-nc/4.0/.

\section{ORCID iDs}

Takuya Sekiguchi http://orcid.org/0000-0003-4642-854X

Yoshihiro Hagiwara http://orcid.org/0000-0002-2992-2178

Yumi Sugawara http://orcid.org/0000-0002-0197-6772

\section{REFERENCES}

1 Vina J, Sanchis-Gomar F, Martinez-Bello V, et al. Exercise acts as a drug; the pharmacological benefits of exercise. $\mathrm{Br} J$ Pharmacol 2012;167:1-12

2 Blair SN, Kohl HW, Paffenbarger RS, et al. Physical fitness and all-cause mortality. A prospective study of healthy men and women. JAMA 1989;262:2395-401.

3 Nikander R, Sievänen $\mathrm{H}$, Heinonen A, et al. Targeted exercise against osteoporosis: a systematic review and meta-analysis for optimising bone strength throughout life. BMC Med 2010;8:47

4 Zampieri S, Pietrangelo L, Loefler S, et al. Lifelong physical exercise delays age-associated skeletal muscle decline. J Gerontol A Biol Sci Med Sci 2015;70:163-73.

5 Pinto RZ, Ferreira PH, Kongsted A, et al. Self-Reported moderate-tovigorous leisure time physical activity predicts less pain and disability over 12 months in chronic and persistent low back pain. Eur J Pain 2014;18:1190-8.

6 Dumith SC, Hallal PC, Reis RS, et al. Worldwide prevalence of physical inactivity and its association with human development index in 76 countries. Prev Med 2011;53:24-8.

7 World Health Organization. Prevalence of insufficient physical activity among adults, 2018. Available: https://apps.who.int/gho/data/node. main.A893?lang=en

8 Guthold R, Stevens GA, Riley LM, et al. Worldwide trends in insufficient physical activity from 2001 to 2016: a pooled analysis of 358 population-based surveys with 1.9 million participants. Lancet Glob Health 2018;6:e1077-86.

9 Pan A, Liu L, Wang C, et al. Association of public health interventions with the epidemiology of the COVID-19 outbreak in Wuhan, China. JAMA 2020;323:1915-23.

10 Wu Z, McGoogan JM. Characteristics of and important lessons from the coronavirus disease 2019 (COVID-19) outbreak in china: summary of a report of 72314 cases from the chinese center for disease control and prevention. JAMA 2020;323:1239-42.

11 Wilder-Smith A, Freedman DO. Isolation, quarantine, social distancing and community containment: pivotal role for old-style public health measures in the novel coronavirus (2019-nCoV) outbreak. J Travel Med 2020;27:taaa020.

12 Nussbaumer-Streit B, Mayr V, Dobrescu Al, et al. Quarantine alone or in combination with other public health measures to control COVID-19: a rapid review. Cochrane Database Syst Rev 2020;9:CD013574.

13 Tremblay MS, Aubert S, Barnes JD, et al. Sedentary behavior research network (SBRN) - terminology consensus project process and outcome. Int J Behav Nutr Phys Act 2017;14:75.

14 Hoy DG, Protani M, De R, et al. The epidemiology of neck pain. Best Pract Res Clin Rheumatol 2010;24:783-92.

15 Ministry. Summary report of comprehensive survey of living conditions 2010 in Japan. of health, labour and welfare, 2017. Available: http://www.mhlw.go.jp/english/database/db-hss/dl/report gaikyo_2010.pdf

16 Takasawa E, Yamamoto A, Kobayashi T, et al. Characteristics of neck and shoulder pain in the Japanese general population. J Orthop Sci 2015;20:403-9.

17 Global Burden of Disease Study 2013 Collaborators. Global, regional, and national incidence, prevalence, and years lived with disability for 301 acute and chronic diseases and injuries in 188 countries, 19902013: a systematic analysis for the global burden of disease study 2013. Lancet 2015;386:743-800.

18 Japan NPAo. Countermeasures for the great East Japan earthquake, 2018. Available: https://www.npa.go.jp/news/other/earthquake2011/ pdf/higaijokyo.pdf

19 Tomata Y, Suzuki Y, Kawado M, et al. Long-Term impact of the 2011 great East Japan earthquake and tsunami on functional disability among older people: a 3-year longitudinal comparison of disability prevalence among Japanese municipalities. Soc Sci Med 2015;147:296-9.

20 Murakami H, Yoshimura E, Ishikawa-Takata K, et al. The longitudinal change in physical activity among great East Japan earthquake victims living in temporary housing. Nihon Koshu Eisei Zasshi 2014;61:86-92.

21 Sekiguchi T, Hagiwara Y, Sugawara Y, et al. Influence of subjective economic hardship on new onset of neck pain (so-called: katakori) in the chronic phase of the great East Japan earthquake: a prospective cohort study. J Orthop Sci 2018;23:758-64.

22 Hestbaek L, Leboeuf-Yde C, Kyvik KO, et al. The course of low back pain from adolescence to adulthood: eight-year follow-up of 9600 twins. Spine 2006;31:468-72.

23 Mansfield M, Thacker M, Spahr N, et al. Factors associated with physical activity participation in adults with chronic cervical spine pain: a systematic review. Physiotherapy 2018;104:54-60.

24 Cimmino MA, Ferrone C, Cutolo M. Epidemiology of chronic musculoskeletal pain. Best Pract Res Clin Rheumatol 2011;25:173-83.

25 Hush JM, Michaleff Z, Maher CG, et al. Individual, physical and psychological risk factors for neck pain in Australian office workers: a 1-year longitudinal study. Eur Spine J 2009;18:1532-40.

26 Sekiguchi T, Hagiwara Y, Sugawara Y, et al. Moving from prefabricated temporary housing to public reconstruction housing and social isolation after the great East Japan earthquake: a longitudinal study using propensity score matching. BMJ Open 2019;9:e026354.

27 Ministry. Comprehensive survey of living conditions. of health labour and welfare, 2017. Available: http://www.mhlw.go.jp/english/ database/db-hss/cslc.html

28 Yabe Y, Hagiwara Y, Sekiguchi T, et al. Influence of living environment and subjective economic hardship on new-onset of low back pain for survivors of the great East Japan earthquake. J Orthop Sci 2017;22:43-9.

29 Carroll LJ, Hogg-Johnson S, van der Velde G, et al. Course and prognostic factors for neck pain in the general population: results of the bone and joint decade 2000-2010 Task force on neck pain and its associated disorders. J Manipulative Physiol Ther 2009;32:S87-96.

30 McLean SM, May S, Klaber-Moffett J, et al. Risk factors for the onset of non-specific neck pain: a systematic review. J Epidemiol Community Health 2010;64:565-72.

31 Croft PR, Lewis M, Papageorgiou AC, et al. Risk factors for neck pain: a longitudinal study in the general population. Pain 2001:93:317-25.

32 Hill J, Lewis M, Papageorgiou AC, et al. Predicting persistent neck pain: a 1-year follow-up of a population cohort. Spine 2004;29:1648-54.

33 Strine TW, Hootman JM. Us national prevalence and correlates of low back and neck pain among adults. Arthritis Rheum 2007;57:656-65.

34 Lubben J, Blozik E, Gillmann G, et al. Performance of an abbreviated version of the Lubben social network scale among three European 
community-dwelling older adult populations. Gerontologist 2006;46:503-13.

35 Suzuki Y, Fukasawa M, Obara A, et al. Mental health distress and related factors among prefectural public servants seven months after the great East Japan earthquake. J Epidemiol 2014;24:287-94.

36 Okajima I, Nakajima S, Kobayashi M, et al. Development and validation of the Japanese version of the Athens insomnia scale. Psychiatry Clin Neurosci 2013;67:420-5.

37 Strain T, Brage S, Sharp SJ, et al. Use of the prevented fraction for the population to determine deaths averted by existing prevalence of physical activity: a descriptive study. Lancet Glob Health 2020;8:e920-30.
38 Bowden Davies KA, Sprung VS, Norman JA, et al. Short-term decreased physical activity with increased sedentary behaviour causes metabolic derangements and altered body composition: effects in individuals with and without a first-degree relative with type 2 diabetes. Diabetologia 2018;61:10.1007/s00125-0184603-5:1282-94.

39 Nilsen TIL, Holtermann A, Mork PJ. Physical exercise, body mass index, and risk of chronic pain in the low back and neck/shoulders: longitudinal data from the Nord-Trondelag health study. Am J Epidemiol 2011:174:267-73.

40 Thivel D, Tremblay A, Genin PM, et al. Physical activity, inactivity, and sedentary behaviors: definitions and implications in occupational health. Front Public Health 2018;6:288. 